\title{
Pengaruh Perkembangan Bahasa Terhadap Perkembangan Kognitif Anak Usia 1-3 Tahun
}

\author{
Fitri Hartanto, Hendriani Selina, Zuhriah H, Saldi Fitra \\ Bagian Ilmu Kesehatan Anak, Fakultas Kedokteran Universitas Diponegoro / RS Dr. Kariadi Semarang
}

Latar belakang. Kemampuan bahasa merupakan salah satu indikator perkembangan kognitif anak. Deteksi dini masalah perkembangan anak sangat menentukan keberhasilan dalam memaksimalkan plastisitas otak pada kompensasi penyimpangan perkembangan.

Tujuan. Mengetahui pengaruh perkembangan bahasa terhadap perkembangan kognitif anak usia 1-3 tahun. Metode. Penelitian potong lintang pada kunjungan pasien Poliklinik Tumbuh Kembang Anak RS Dr. Kariadi Semarang, usia subjek 1-3 tahun. Kriteria inklusi keterlambatan bicara, gizi baik, tidak memiliki kelainan kongenital, gangguan neurologi, dan gangguan pendengaran. Dilakukan pemeriksaan kemampuan bahasa dengan Denver II kemudian ditentukan DQ (developmental quotients) menggunakan CAPUTE scale. Untuk menentukan gangguan pendengaran dilakukan konsultasi dengan Bagian THT dan pemeriksaan BERA. Data dianalisis secara statistik dengan uji-t.

Hasil. Didapatkan kasus $(\mathrm{n}=36)$ dan kontrol ( $\mathrm{n}=36$ ), jumlah sampel laki-laki pada kasus $77.8 \%$. Pada kelompok kontrol rerata DQ CAT (cognitive adaptive test) 91,4 ( $\left.\mathrm{SD}_{ \pm} 5,6\right)$, CLAMS (clinical linguistic \& auditory milestone scale) 90,1 ( $\left.\mathrm{SD}_{ \pm} 6,1\right)$ sedangkan pada kasus rerata $\mathrm{DQ}$ CAT 82,7 ( $\left.\mathrm{SD}_{ \pm} 6,7\right)$, CLAMS 57,9 $\left(\mathrm{SD}_{ \pm} 11,2\right)$. Hasil Uji- $t$ didapat adjusted $\mathrm{R}^{2} \quad 0,415 \quad(p=0,000)$.

Kesimpulan. Terdapat pengaruh perkembangan bahasa terhadap perkembangan kognitif pada anak usia 1-3 tahun. Sari Pediatri 2011;12(6):386-90.

Kata kunci: perkembangan, bahasa, kognitif, capute scale

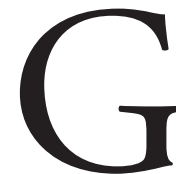
angguan perkembangan berbahasa adalah ketidakmampuan atau keterbatasan dalam menggunakan simbol linguistik untuk berkomunikasi secara verbal atau keterlambatan kemampuan perkembangan bicara dan bahasa anak sesuai kelompok umur, jenis kelamin, adat istiadat, dan kecerdasannya. ${ }^{1}$ Beberapa data menunjukan

Alamat korespondensi:

Dr. Fitri Hartanto, Sp.A, Bagian Ilmu Kesehatan Anak Fakultas Kedokteran Universitas Diponegoro/RS Dr. Kariadi Semarang. Jl. Dr Soetomo 16-18 Semarang. Telp.08122841691, E-mail: fe3h@yahoo.com angka kejadian anak dengan keterlambatan bicara (speech delay) cukup tinggi. Gangguan komunikasi dan gangguan kognitif merupakan bagian dari gangguan perkembangan anak, terjadi pada sekitar $8 \% .^{2}$ Data dari RS Dr. Kariadi selama tahun 2007 di Poliklinik Tumbuh Kembang Anak didapatkan 22,9\% dari 436 kunjungan baru datang dengan keluhan terlambat bicara, $13(2,98 \%)$ di antaranya didapatkan gangguan perkembangan bahasa. ${ }^{3}$

Perkembangan bahasa merupakan salah satu indikator perkembangan menyeluruh dari kemampuan kognitif anak yang berhubungan dengan keberhasilan 
di sekolah. ${ }^{4,5}$ Keterlambatan perkembangan pada awal kemampuan berbahasa dapat mempengaruhi berbagai fungsi dalam kehidupan sehari-hari. Selain itu mempengaruhi kehidupan personal sosial, juga akan menimbulkan kesulitan belajar, bahkan kemampuan hambatan dalam bekerja kelak. Identifikasi dan intervensi secara dini dapat mencegah terjadinya gangguan dan hambatan tersebut. ${ }^{6,7,8}$

Tiga tahun pertama kehidupan merupakan periode kritis kehidupan anak. Plastisitas otak maksimal pada beberapa tahun pertama kehidupan dan berlanjut dengan kecepatan yang lebih lambat. Pengalaman sensorik, stimulasi dan pajanan bahasa selama periode ini dapat menentukan sinaptogenesis, mielinisasi, dan hubungan sinaptik . Prinsip "gunakanlah atau kehilangan" dan "gunakan serta kembangkanlah" didasarkan pada prinsip plastisitas otak. ${ }^{9,10}$ Oleh sebab itu bila gangguan bicara dan bahasa tidak diterapi dengan tepat akan terjadi gangguan kemampuan membaca, kemampuan verbal, perilaku, penyesuaian psikososial dan kemampuan akademis yang buruk. ${ }^{11}$ Anak yang mengalami kelainan bahasa pada pra sekolah 40\% hingga $60 \%$ akan mengalami kesulitan belajar dalam bahasa tulisan dan mata pelajaran akademik. ${ }^{12}$ Sidiarto $^{14}$ (2002) menyebutkan bahwa anak yang dirujuk dengan kesulitan belajar spesifik, lebih dari 60\% mempunyai keterlambatan bicara. Sedang Rice $^{13}$ menyebutkan, apabila disfasia perkembangan tidak di atasi secara dini, 40\%-75\% anak akan mengalami kesulitan untuk membaca. Oleh sebab itu deteksi dini masalah perkembangan pada anak sangat menentukan keberhasilan kita yang membuat plastisitas otak maksimal di dalam melakukan kompensasi penyimpangan perkembangan.

\section{Metode}

Penelitian dilakukan pada anak usia 1-3 tahun di Poliklinik Tumbuh Kembang Anak RS Dr. Kariadi Semarang, selama periode Juli - Desember 2008. Kriteria inklusi adalah keterlambatan bicara, gizi baik, tidak memiliki kelainan kongenital, tidak terdapat gangguan neurologi, dan gangguan pendengaran. Kelompok kontrol adalah kelompok usia sama yang tidak mengalami keterlambatan bicara. Skrining awal keterlambatan bahasa menggunakan Denver II kemudian dilanjutkan dengan pemeriksaan kemampuan bahasa dan kognitif dengan CAPUTE Scale yang terdiri dari $C A T$ dan $C L A M$. Untuk menyingkirkan gangguan pendengaran dilakukan konsultasi dengan Bagian THT dan dilakukan tes BERA. Tes CLAMS merupakan alat skrining untuk mengetahui kemampuan perkembangan bicara, bahasa dan auditori, sedangkan CAT digunakan untuk mengetahui kemampuan perkembangan visualmotor dan kognitif adaptif dengan hasil akhir kedua pemeriksaan menggunakan nilai DQ. Data dianalisis dengan uji- $t$ menggunakan komputer.

\section{Hasil}

Penelitian melibatkan 72 subjek, didapatkan 36 subjek dengan keterlambatan perkembangan bahasa dan kontrol 36 subjek. Subjek terdiri atas 53 anak laki laki dan 19 perempuan (Tabel 1 ).

Dari analisis data menggunakan uji- $t$ berpasangan didapatkan hubungan antara CLAMS dan CAT dengan nilai adjusted $R^{2} \quad 0,415 ; p=0.000$ artinya semakin tinggi nilai CLAMS semakin tinggi pula nilai CAT, begitu pula sebaliknya (Tabel 2).

Tabel 1. Karakteristik subyek berdasarkan kelompok umur dan jenis kelamin

\begin{tabular}{lcc}
\hline Karakteristik & $\begin{array}{c}\text { Kasus } \\
(\mathrm{n}=36)\end{array}$ & $\begin{array}{c}\text { Kontrol } \\
(\mathrm{n}=36)\end{array}$ \\
\hline $\begin{array}{l}\text { Umur (bulan), rerata } \pm \text { SB } \\
\text { Jenis kelamin }\end{array}$ & $28,5 \pm 6,06$ & $27,9 \pm 7,48$ \\
Laki laki & 28 & 25 \\
Perempuan & 8 & 11 \\
Tingkat pendidikan ibu & & \\
SD & 2 & 3 \\
SLTP & 3 & 2 \\
SLTA & 4 & 13 \\
Diploma & 14 & 6 \\
Sarjana & 13 & 12 \\
\hline
\end{tabular}

Tabel 2. Nilai DQ CAT dan DQ CLAMS

\begin{tabular}{lcccc}
\hline Skrining & Kasus & Nilai DQ & & \\
& Kontrol & Adjusted $\mathrm{R}^{2}$ & $p^{*}$ \\
\hline CLAMS & $57,9(\mathrm{SD} \pm 11,2)$ & $90,1(\mathrm{SD} \pm 6,1)$ & & \\
CAT & $82,7(\mathrm{SD} \pm 6,7)$ & $91,4(\mathrm{SD} \pm 5,6)$ & 0,415 & 0,000 \\
\hline
\end{tabular}

${ }^{*} \mathrm{Uji}-t$ 


\section{Pembahasan}

American Academy of Pediatrics (AAP) merekomendasikan agar melakukan survailans perkembangan (developmental survailance) pada setiap anak sehat dan melakukan skrining perkembangan (developmental scrining) pada anak usia 9, 18, dan 30 bulan atau anak yang dicurigai memiliki keterlambatan atau kelainan perkembangan. ${ }^{6,14}$ Apabila didapatkan gangguan perkembangan maka harus dilakukan evaluasi medis dan perkembangan (developmental assesment) agar dapat dilakukan intervensi dini pada anak. ${ }^{14}$.

Terdapat perbedaan antara bicara dan bahasa. Bicara adalah pengucapan, yang menunjukkan keterampilan seseorang mengucapkan suara dalam suatu kata. Bahasa berarti menyatakan dan menerima informasi dalam suatu cara tertentu. Bahasa merupakan salah satu cara berkomunikasi. Bahasa reseptif adalah kemampuan untuk mengerti apa yang dilihat dan apa yang didengar. Bahasa ekspresif adalah kemampuan untuk berkomunikasi secara simbolis baik visual (menulis, memberi tanda) atau auditorik. Seorang anak yang mengalami gangguan berbahasa mungkin saja dapat mengucapkan suatu kata dengan jelas tetapi ia tidak dapat menyusun dua kata dengan baik. Sebaliknya, ucapan seorang anak mungkin sedikit sulit untuk dimengerti, tetapi ia dapat menyusun kata kata yang benar untuk menyatakan keinginannya. Masalah bicara dan bahasa sebenarnya berbeda tetapi kedua masalah ini sering kali tumpang tindih. ${ }^{15}$

Penelitian kami menunjukan jenis kelamin anak dengan keterlambatan bahasa lebih banyak laki laki $(77,8 \%)$ dibandingkan perempuan, sesuai dengan pernyataan Sidiarto yang menyatakan rasio laki-laki dibandingkan perempuan mencapai $8: 1^{14}$

Webster, ${ }^{15}$ pada penelitian case-control mengenai gangguan perkembangan bahasa pada anak usia 7 sampai dengan 13 tahun di dapatkan bahwa pada anak dengan gangguan perkembangan bahasa menunjukkan nilai rata-rata pada penilaian Peabody picture vocabulary, kognitif, kemampuan motorik serta tingkat intelegensi. Keterlambatan gerakan motorik terjadi pada $70 \%$ anak dengan gangguan perkembangan bahasa dibandingkan dengan kelompok kontrol (8\%). Tingkat kemampuan motorik setaraf dengan kemampuan berbahasa namun tidak berhubungan dengan fungsi kognitif nonverbal. Penemuan tersebut mendukung hipotesis adanya faktor biologis kritis pada fungsi motorik dan bahasa.
Kemampuan berbahasa ekspresif secara positif juga berhubungan dengan tingkat pendidikan ibu. ${ }^{16}$ Pada penelitian ini menunjukkan bahwa tingkat pendidikan ibu pada kelompok kasus yang mengalami gangguan perkembangan bahasa sebagian besar berpendidikan diploma dan sarjana. Bahasa merupakan salah satu parameter dalam perkembangan anak. Kemampuan bicara dan bahasa melibatkan perkembangan kognitif, sensorimotor, psikologis, emosi dan lingkungan sekitar anak. Kemampuan bahasa pada umumnya dapat dibedakan atas kemampuan reseptif (mendengar dan memahami) dan kemampuan ekspresif (berbicara). Kemampuan bicara lebih dapat dinilai dari kemampuan lainnya sehingga pembahasan mengenai kemampuan bahasa lebih sering dikaitkan dengan kemampuan berbicara. Kemahiran dalam bahasa dan berbicara dipengaruhi oleh faktor intrinsik (dari anak) dan faktor ekstrinsik (dari lingkungan). Faktor intrinsik yaitu kondisi pembawaan sejak lahir termasuk fisiologi dari organ yang terlibat dalam kemampuan bahasa dan berbicara. Sedangkan faktor ekstrinsik dapat berupa stimulus yang ada di sekeliling anak, misalnya perkataan yang didengar atau ditujukan kepada si anak. ${ }^{17}$

Persentase tingkat pendidikan ibu yang lebih tinggi pada kelompok kasus dibandingkan kelompok kontrol, kemungkinan berhubungan dengan stimulasi pada kelompok kasus. Stimulasi yaitu kegiatan merangsang kemampuan dasar anak agar anak tumbuh dan berkembang secara optimal. Setiap anak perlu mendapat stimulasi rutin sedini mungkin dan terus menerus pada setiap kesempatan yang dapat dilakukan oleh ibu, ayah, pengasuh, maupun orang-orang terdekat dalam kehidupan sehari hari. Kurangnya stimulasi dapat menyebabkan gangguan yang menetap. ${ }^{18}$ Deteksi dini terhadap gangguan perkembangan bahasa sangat menentukan nilai intervensi yang akan diberikan sehingga akan mempengaruhi perkembangan kognitif secara menyeluruh. Penelitian cluster randomized trial yang dilakukan oleh Heleen dkk $^{18}$ (2007) mengenai skrining keterlambatan bahasa pada toddlers dengan pengaruhnya pada kemampuan sekolah dan perkembangan bahasa pada saat umur 8 tahun, menunjukkan bahwa skrining tersebut dapat menurunkan jumlah anak yang membutuhkan pendidikan khusus dan memberikan perbaikan pada kemampuan perkembangan bahasa. Pada saat usia 8 tahun hanya 2,7\% pada kelompok yang diberikan intervensi dibandingkan dengan 3,7\% kelompok kontrol yang membutuhkan sekolah khusus. 
Fitri Hartanto dkk: Pengaruh perkembangan bahasa terhadap perkembangan kognitif anak

Penelitian yang dilakukan oleh Frances mengenai risiko perilaku, persepsi dan psikososial orang tua dalam mempengaruhi perkembangan anak memberikan hasil perilaku orang tua yang positif dan persepsi negatif dari anak mengindikasikan kemampuan anak mendekati kurang dari dua standar baku di bawah nilai rata-rata pada skrinning Brigance. Faktor risiko psikososial berhubungan dengan sedikitnya perilaku positif orang tua dan persepsi negatif termasuk lebih dari tiga anak dalam satu rumah, seringnya berpindah-pindah, keterbatasan penggunaan bahasa asing dan depresi pada orang tua. Kekurangan perilaku orang tua yang positif ditambah dengan persepsi negatif dari anak baik dengan ataupun tanpa faktor risiko psikososial memberikan pengaruh negatif terhadap perkembangan anak yang terlihat pada awal usia enam bulan. Perkembangan bahasa berisiko terjadi ketika terdapat masalah pada orang tua. Hasil penelitian kami menyimpulkan pentingnya promotif terhadap perkembangan awal dengan orang tua, fokus pada kemampuan pembicaraan yang dilakukan oleh orang tua, bermain, dan membaca dengan anak serta kebutuhan intervensi pada berbagai masalah yang bertanggungjawab menjadi faktor risiko psikososial. $^{19}$

Identifikasi dini keterlambatan bahasa harus memecahkan dua masalah utama yaitu masalah ketersediaan informasi yang dapat dipercaya dari seorang anak pada usia berapa ketika mereka mengalami keterbatasan dalam kemampuan berkomunikasi. Selanjutnya, teknik pengukuran harus cost-effective dengan menghargai waktu secara professional dan secara luas mampu diaplikasikan untuk anak pada berbagai tingkat sosial dan latarbelakang bahasa termasuk bilingual. Masalah kedua adalah pada interpretasi hasil dari proses identifikasi. Banyak anak yang mengalami keterlambatan bahasa pada usia 24 sampai 30 bulan akan mengejar dalam beberapa tahun kemudian dan tidak memerlukan intervensi. Tantangan yang ada adalah dalam mengidentifikasi dan menggunakan informasi lain yang relevan dalam memperbaiki keputusan diagnosis mengenai seorang anak secara individual untuk mencegah gangguan perkembangan yang lebih signifikan. ${ }^{20}$ Anak yang hanya mengalami keterlambatan bahasa ekspresif akan memiliki prognosis yang baik, namun demikian adanya keterlambatan bahasa awal merupakan indikator beberapa masalah neurodevelopmental. Keterlambatan bahasa merefleksikan specific language impairment yaitu tertinggal pada bahasa ekspresif ataupun kekurangan bahasa ekspresif dan reseptif yang berhubungan dengan kelemahan kognitif secara umum. ${ }^{21-22}$

Disimpulkan pada penelitian kami bahwa terdapat pengaruh antara perkembangan bahasa terhadap perkembangan kognitif pada anak usia 1-3 tahun. Perlu dilakukan penelitian lebih lanjut untuk mengetahui apakah yang mempengaruhi perkembangan kognitif hanya pada bahasa ekspresif atau reseptif atau keduanya.

\section{Daftar pustaka}

1. Sidiarto L. Berbagai gejala disfungsi minimal otak (DMO) yang berwujud kesulitan belajar spesifik dan permasalahannya. Dalam: Mudjiman H, Yusup M, penyunting. DMO dan kesulitan belajar anak. Pusat Penelitian Universitas Sebelas Maret Surakarta, 1990.

2. Scheffner F, Vogel D, Astern R, Burgess J, Connealy RT, Salerno K. Screning for commonication and cognitive disorder in infant and toddler. Diunduh dari: http:// goliath.ecnext.com

3. Klinik Tumbuh Kembang Anak RS. Dr. Kariadi. Studi pendahuluan disfasia perkembangan. Semarang; 2007.

4. Nelson HD, Nygren MA, Walker M, Panoscha R. Screening for speech and Language delay in preschool children: systemic evidence review of the US preventive service task force. Pediatrics 2006;117:293-317.

5. Low J, Boyle J, Harris F, Harkness A, Nye C, Screening for speech and language delay: asystemic review of the literature. Health Technology Assesment 1998;2:1-5.

6. American Academy of Pediatrics. Committe on children with disabilities. Role of the Pediatrician in family-centered early intervention service. Pediatrics 2001;107:1155-7.

7. Leung AKC, Kao CP. Evaluation and management of the child with speech delay. American Academy of Family Physician; June 1999. Diunduh dari: http://www.aafp.org/ afp/990600ap/3121.html

8. Vincer MJ, Cake H, Graven M, Dodds L, McHugh S, Fraboni T. A population-based study to determine the performance of the cognitive adaftive test/clinical linguistic and auditory milestone scale to predict the mental developmental index at 18 months on the bayley scale of infant development -II in very preterm infants. Pediatric 2005;116:864-7.

9. Jonhston MV. Clinical disorder of brain plasticity. Brain Dev 2004; 26:73-80.

10. Mundkur N. Neuroplasticity in children. Indian J Pediatr 
2005;72:855-7.

11. Leung KA, Kao PC. Evaluation and management of the child with speech delay. Am Fam Phys 1999;59:32-45.

12. Kustiowati E. Tinjauan umum gangguan perkembangan bahasa dan bicara pada anak. Dalam simposium Neuropediatri “ Child Who Does Not Speak”. Semarang: Badan Penerbit Universitas Diponegoro; 2002.h.1-5

13. Rice LM. Top ten things you should know about children with spesific language impairmen. The University of Kansas Meeril Advanced Studies Center. Di unduh dari: http://merril.ku.edu/In The Know/Sciencearticles/SLIfacts. html.

14. Sidiarto L. Gangguan perkembangan bahasa dan bicara pada keterlambatan bahasa. dalam simposium neuropediatri " child who does not speak". Semarang : Badan Penerbit Universitas Diponegoro;2002.h.7-13.

15. Webster RI. The clinical spectrum of developmental language impairment in school aged children: language, cognitive and motor findings.Pediatrics 2006;118:1541-9

16. Soetjiningsih. Perkembangan anak dan permasalahannya. Dalam: Narendra MB, Sularyo S, Soetjiningsih, S uyitno H, Ranuh IG, penyunting. Buku Ajar Tumbuh Kembang Anak dan Remaja; Edisi I. Jakarta: Ikatan
Dokter Anak Indonesia. Jakarta: Sagung Seto; 2002.h. 91.

17. Simkin Z, Conti G. Evidence of reading difficulty in subgroups of children with specific language impairmen. Child language teaching and therapy 2006;22;315-31.

18. M.E Heleen. A-Cluster Randomized trial of screening for language delay in toddlers: effect on school performance and language development at age 8 . Pediatrics 2007;120:1317-25

19. Dale Philip, Paterrson Janet. Early identification of language delay. Dalam: Language development and literacy learning disabilities. Department of speech and hearing sciences. USA; 2000.

20. Glascoe Frances, Leew Shirley. Parenting behaviours, perceptions and psychosocial risk : impacts on young children's development. Pediatrics 2010;125:313-9

21. Buschmann Anke. Children with developmental language delay at 24 months of age : results of a diagnostic work-up. Developmental Medicine \& Child Neurology 2008;50:223-9.

22. Heidi M. Feildman evaluation and management of speech and language disorder in preschool children. Pediatr Rev 2005; 26;131-42. 